See Article page 534 .

\section{Commentary: Did you leave a ball inside me?}

\author{
Todd L. Demmy, MD
}

The article by Wildemeersch and colleagues ${ }^{1}$ serves as a warning regarding a complication that probably is more common than their title suggests. The authors documented their case well, with findings extreme enough to be visible on physical examination and imaging. However, it is likely that less severe (partial or temporary) denervation occurs more frequently and may be hidden by adiposity, general rectus muscle underdevelopment, and stoic patient behavior. In my practice, patients occasionally complain of persistent fullness in the same area and wonder whether I might have left a "ball" inside their body.

Beside characteristics already mentioned, there may be anatomic variations, like a dominant neural dermatome, that make some patients more vulnerable to this event. Yet, there are probably many things we can do better as surgeons to prevent neural injury. For instance, we may wish to avoid liberal cautery dissection during port creation and find other ways, like miniature wound protectors, to prevent camera smudging from oozing.

As the authors note, it is also possible that the choice of approach may be a factor. These surgeons noticed this complication during their transition to robotic surgery. Port-site selection varies among surgeons for all types of minimally invasive surgery, including robotic lobectomy. ${ }^{2}$ Unlike other video-assisted thoracoscopic surgery approaches, there is the practical need to keep ports relatively low in the target body cavity to facilitate robotic instrument

\footnotetext{
From the Department of Thoracic Surgery, Roswell Park Comprehensive Cancer Center; and the Department of Surgery, University at Buffalo, Buffalo, NY. Disclosures: The author has disclosed a relationship with Medtronic.

The Journal policy requires editors and reviewers to disclose conflicts of interest and to decline handling or reviewing manuscripts for which they may have a conflict of interest. The editors and reviewers of this article have no conflicts of interest.

Received for publication Sept 27, 2021; revisions received Sept 27, 2021; accepted for publication Oct 6, 2021; available ahead of print Oct 9, 2021.

Address for reprints: Todd L. Demmy, MD, Department of Thoracic Surgery, Roswell

Park Comprehensive Cancer Center, Elm and Carlton St, Buffalo, NY 14263

(E-mail: todd.demmy@ roswellpark.org).

JTCVS Techniques 2021;10:540-1

2666-2507

Copyright (C) 2021 The Author(s). Published by Elsevier Inc. on behalf of The American Association for Thoracic Surgery. This is an open access article under the CC BY-NC-ND license (http://creativecommons.org/licenses/by-nc-nd/4.0/).

https://doi.org/10.1016/j.xjtc.2021.10.004
}

Check for updates

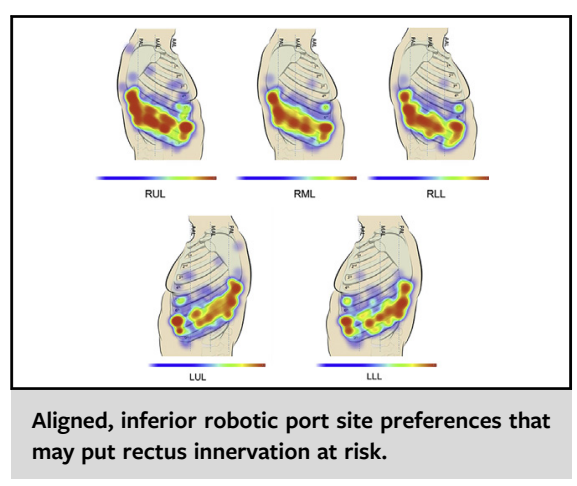

CENTRAL MESSAGE

While complete paralysis may be uncommon, rectus muscle nerve function studies may reveal subclinical injuries useful in understanding post-thoracotomy pain syndromes better.

movement (Figure 1). This places ports in the range of the intercostal nerves affecting the recti. There is also the tendency to align them within one interspace. While this may keep intercostal neuralgia down to one vulnerable nerve, it also amplifies its incremental risk for damage.

Another anesthetic practice used by these surgeons routinely was the use of cryoanalgesia. While this was associated with delayed neuralgia when first introduced, modern delivery systems may be less likely to cause this. ${ }^{3,4}$ In fact, the authors did not notice this complication for many nonrobotic case approaches. Yet, there may be an additive effect on injury in the same way as iced slush used in cardiac surgery increased the risk of phrenic nerve injuries from the devascularization caused by internal mammary harvest. ${ }^{5}$ Unfortunately, it is difficult to attribute the effects of additive injuries on the causation of infrequent events.

While this complication may be uncommon, it is likely that methods introduced to study and prevent it will be good for our understanding of post-thoracoscopic and thoracotomy pain. Pain management varies widely between institutions because of the many permutations of interventions used to deal with its multifactorial etiology. It would be interesting to map rectus innervation to prevent injury. However, if we detect postoperative dysfunction, then it may correlate with chronic pain and the relative trauma of our surgical techniques. Much pain research has focused on nociceptive afferent pathways, which are hard to monitor 

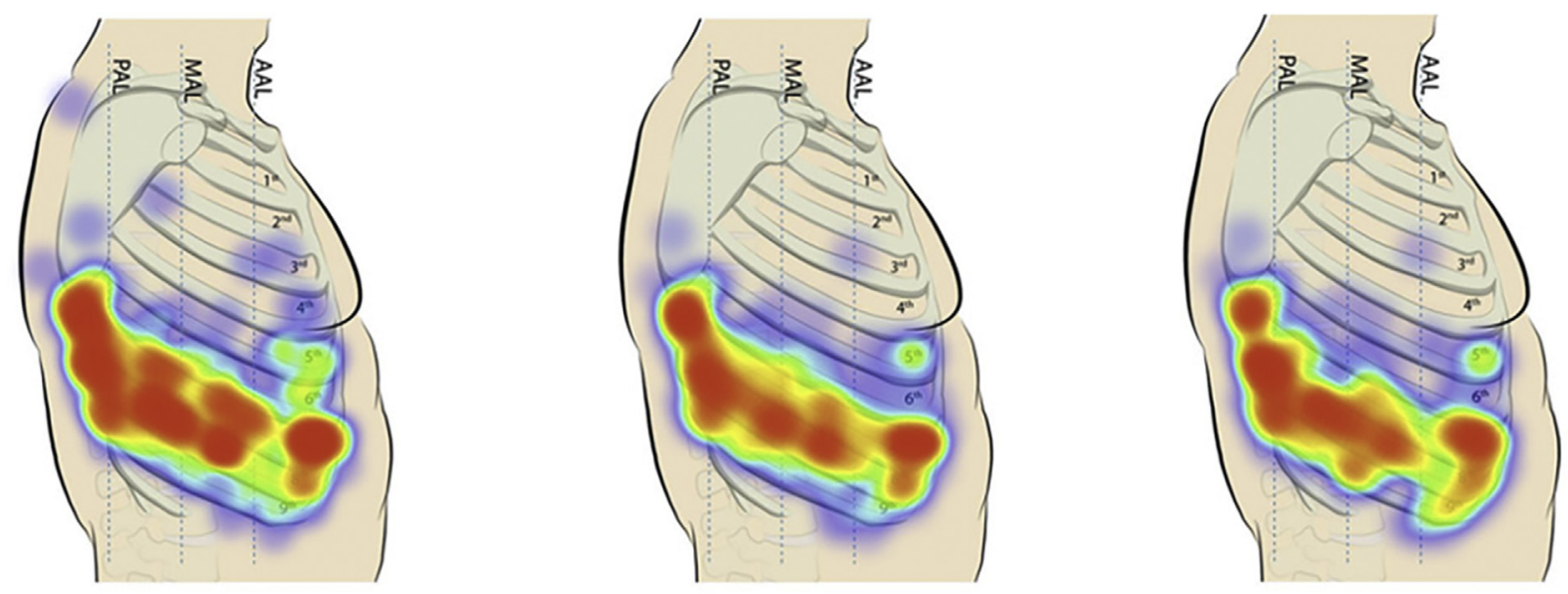

RUL

RML

RLL

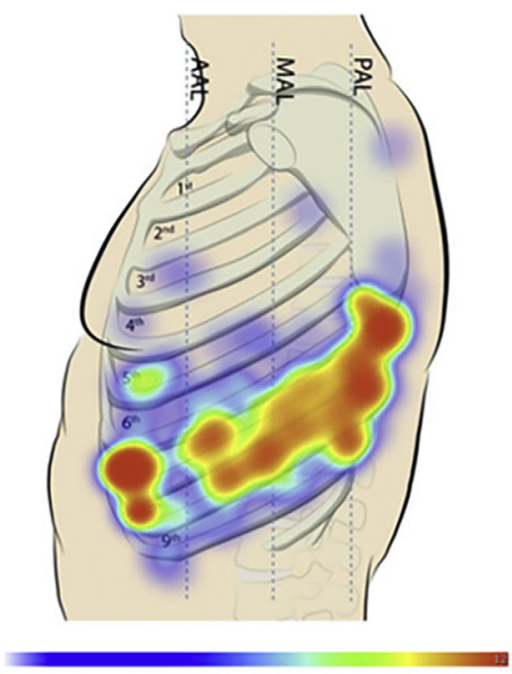

LUL

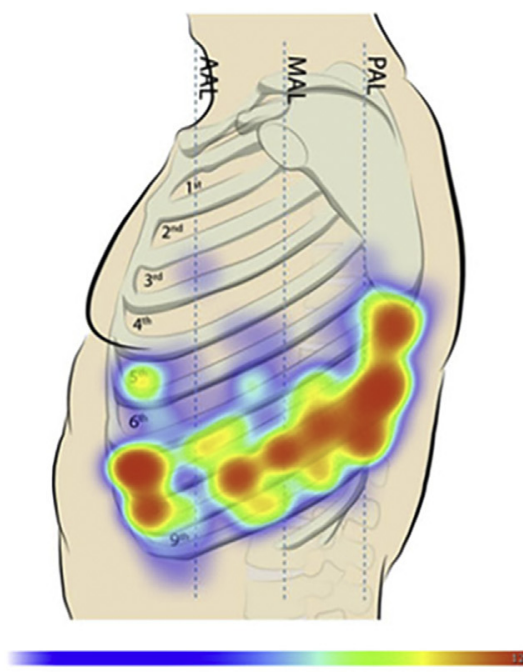

LLL

FIGURE 1. Heat map of robotic port site preference from a sample of robotic thoracic surgeons. Notice how the ports tend to converge along inferior interspaces responsible for superior rectus innervation. Reprinted with permission from Oh and colleagues. ${ }^{2} R U L$, Right upper lobe; $R M L$, right middle lobe; $R L L$, right lower lobe; $L U L$, left upper lobe; $L L L$, left lower lobe.

under anesthesia. Perhaps muscle relaxant avoidance and serial rectus (efferent) testing while we perform our operations will tell us if port incisions are likely to trigger postoperative pain or rectus dysfunction.

\section{References}

1. Wildemeersch D, Yogeswaran SK, Vyncke G, Meeus I, Wielandt T, Hans G, et al. Upper rectus abdominis paralysis after robot-assisted thoracic oncology surgery with cryoanalgesia: a rare complication. J Thorac Cardiovasc Surg Tech. 2021; 10:534-7.
2. Oh DS, Tisol WB, Cesnik L, Crosby A, Cerfolio RJ. Port strategies for robotassisted lobectomy by high-volume thoracic surgeons: a nationwide survey. Innovations (Phila). 2019;14:545-52.

3. Graves CE, Moyer J, Zobel MJ, Mora R, Smith D, O'Day M, et al. Intraoperative intercostal nerve cryoablation during the Nuss procedure reduces length of stay and opioid requirement: a randomized clinical trial. J Pediatr Surg. 2019;54: 2250-6.

4. Muller LC, Salzer GM, Ransmayr G, Neiss A. Intraoperative cryoanalgesia for postthoracotomy pain relief. Ann Thorac Surg. 1989;48:15-8.

5. Curtis JJ, Nawarawong W, Walls JT, Schmaltz RA, Boley T, Madsen R, et al Elevated hemidiaphragm after cardiac operations: incidence, prognosis, and relationship to the use of topical ice slush. Ann Thorac Surg. 1989;48:764-8. 